\title{
Evaluation Polyphenol Content and Antioxidant Activity in Extracts of Cucurbita spp
}

\author{
Gabriela M. Valenzuela*, Ariadna S. Soro, Alicia L. Tauguinas, Mabel R. Gruszycki, \\ Alicia L. Cravzov, María C. Giménez, Andrea Wirth \\ Universidad Nacional del Chaco Austral, Chaco, Argentina \\ Email: "gabriela@uncaus.edu.ar
}

Received 12 April 2014; revised 21 May 2014; accepted 30 May 2014

Copyright (C) 2014 by authors and OALib.

This work is licensed under the Creative Commons Attribution International License (CC BY). http://creativecommons.org/licenses/by/4.0/

\section{Abstract}

It is increasingly evident that oxidative stress and the presence of free radicals are a major cause of many disease processes that may aggravate the disease course, or create new effects that could cause further alterations in patient's health or impair their quality of life. The purpose of this study was to determine the antioxidant activity of extracts from seeds of four varieties of Cucurbita spp: (Hybrid between $C$. moschata and C. maxima Duchesne ex Lam) Tetsukabuto, C. mixta Pangalo (calabaza rayada), $C$. moschata (Duchesne ex Lam.) Duchesne ex Poir. (coreanito) and $C$. maxima Duchesne (calabaza plomo), in relation to their content of total phenols and flavonoids. Extracts of decreasing polarity were obtained using the following solvents: acidified water, methanol, acetone and ethyl acetate, the total phenols and flavonoids were quantified by the FolinCiocalteau and complexation with $\mathrm{AlCl}_{3}$ to $5 \%$ respectively. To determine the antioxidant activity of extracts bleaching technique free radical 2,2-diphenyl-1-picrylhydrazyl (DPPH) was used. The total phenolic content was to Tetsukabuto $(165.48 \pm 0.94)$, calabaza rayada $(275.10 \pm 6.86)$, coreanito (118.79 \pm 3.72$)$ calabaza plomo $(212.87 \pm 751)(\mathrm{mol} \mathrm{GAE} / \mathrm{g}$ of sample). Flavonoids values ranged from $(32.03 \pm 1.39)$ and $(96.63 \pm 1.14)$ (quercetin $\mathrm{mg} / \mathrm{g}$ sample). The antioxidant activity expressed as median inhibitory concentration (IC50) showed the following results: Tetsukabuto $(117.69 \pm 5.81)$ calabaza rayada $(77.75 \pm 3.64)$; coreanito $(110.67 \pm 1.70)$, calabaza plomo $(87.39 \pm$ 8.64) $(\mathrm{mg} / \mathrm{ml})$. A one-way analysis of variance showed significant differences $(p<0.05)$ among the varieties studied. The results obtained show a clear relationship between the content of total phenolics and flavonoids with antioxidant activity, with $C$. mixta Pangalo variety showed higher antioxidant activity and can be considered a source of natural antioxidants to produce a beneficial effect on health.

"Corresponding author. 


\section{Keywords}

\section{Antioxidant Activity, Seeds, Pumpkin}

\section{Introduction}

Pumpkin seeds (Cucurbita spp) from antiquity have multiple uses in different countries as food and for medicinal purposes [1]. The man from the beginning in a process of relationship with the environment always looked at nature, how to find cures to diseases that afflicted him; empirically in their search for the healing of their ailments, was discovering the effect the proper use of plants and over time researching and extracting their properties [2].

Phenolic compounds or polyphenols are a large group of chemicals with different structures and chemical properties and biological activity, encompassing over 8000 different compounds. The study of oxidative reactions has increased in recent years due to the oxidation of cellular components by the action of free radicals and other factors has been recognized as the cause cellular processes such as aging and numerous diseases such as cancer, Parkinson's disease, Alzheimer's and cardiovascular diseases [3] [4]. Therefore natural antioxidants present in grains, vegetables and fruits have received considerable attention for their potential applications in the prevention of numerous diseases [5].

The search for natural variants is further premise, therefore in this paper the content of total phenols, flavonoids and antioxidant activity in four varieties of seeds Cucurbita spp grown in the province of Chaco is determined: Tetsukabuto (hybrid C. moschata and C. maxima Duchesne ex Lam.), C. mixta Pangalo (calabaza rayada), C. moschata (Duchesne ex Lam.) Duchesne ex Poir. (coreanito) and C. maxima Duchesne (calabaza plomo) (Figure 1).

\section{Materials and Methods}

We proceeded to collecting seeds of different varieties of Cucurbita spp producer in the region. The samples were dried to constant weight and stored in plastic bags, hermetically sealed and identified with labels. Fresh samples of plants (leaf, flower and fruit) were deposited in the Department Pharmacobotany National University of the Chaco Austral for identification.

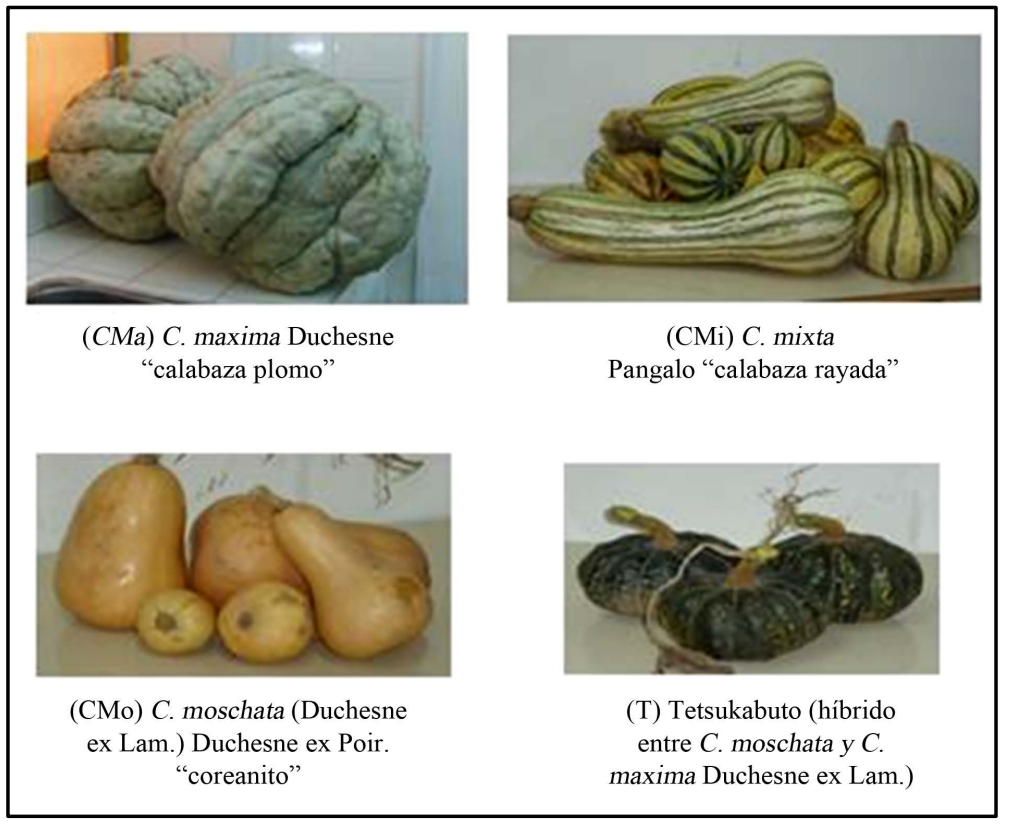

Figure 1. Images of four varieties of Cucurbita spp. 


\subsection{Obtention of Extracts with Solvent Decreasing Polarity}

Ten grams of pumpkin seeds were homogenized in $50 \mathrm{ml}$ of deionized water acidified (2\% acetic acid) using a homogenizer (Ultra-Turrax T25 JANKE and Kunkel, IKA-Labortechnik). The suspension was left at room temperature for $10 \mathrm{~min}$ and centrifuged at $800 \mathrm{rpm}$ for $10 \mathrm{~min}$. The supernatant was collected in a flask and the pellet was treated with $50 \mathrm{ml}$ of water acidified again. The suspension was centrifuged at $800 \mathrm{rpm}$ for $10 \mathrm{~min}$ and the resultant supernatant was combined with the supernatant of the first centrifugation, the remaining pellet was homogenized in $50 \mathrm{ml}$ of acidified methanol (2\% acetic acid) and the aforementioned process is he repeated. Two more solvents, acetone and ethyl acetate, was successively used for extraction of each fraction of the remaining residue. Four pumpkin seed extracts were finally collected an aqueous extract (W), a methanol extract (M), one in acetone (Ac) and another ethyl acetate extract (ACET ETHYL). All fractions were evaporated under reduced pressure and redissolved in a volume of solvent that was originally used for extraction; the extraction process is performed for each of the four varieties of Cucurbita spp studied.

\subsection{Quantification of Total Phenols}

The total phenolic content was determined by the method of [6], which is based on the phenolic compounds reduce the Folin-Ciocalteu (tungsten and molybdate reagent) to form a blue complex that absorbs $765 \mathrm{~nm}$, to 200 ul of sample was added $2 \mathrm{ml}$ of deionized water and $0.2 \mathrm{ml}$ of Folin-Ciocalteu method, after 2 minutes $0.8 \mathrm{ml}$ of $15.9 \%$ sodium carbonate was added, incubated at $50^{\circ} \mathrm{C}$ for 5 minutes and the absorbance at $765 \mathrm{~nm}$ on a UV Visible Spectrophotometer Perkin Elmer Lambda 25 was measured. A calibration curve was performed with an alcoholic solution of galic acid (GA). A stock concentration of $0.1 \mathrm{mg} / \mathrm{ml}$ solution was used, covering a range from 0.002 to $0.035 \mathrm{mg}$ of acid per milliliter of solution. The results were expressed as mol of gallic acid per $\mathrm{g}$ of extract (AG mol/g extract).

\subsection{Quantitation of Total Flavonoids}

The total flavonoid content in the different extracts was determined by the method of [7] with modifications. To an aliquot of $0.2 \mathrm{ml}$ of extract were added $1.8 \mathrm{ml}$ of methanol and $1 \mathrm{ml}$ of ethanol solution of $5 \% \mathrm{AlCl}_{3}$. After one hour incubation at room temperature, the absorbance was measured at $425 \mathrm{~nm}$ on a UV-Visible Spectrophotometer Perkin Elmer Lambda 25. Quercetin solutions were used between 5 - $25 \mathrm{mg} / \mathrm{ml}$, to construct a calibration curve. The total flavonoid content was calculated as mg equivalent of quercetin (QE)/g extract. This procedure was performed with each of the extracts of each variety in triplicate.

\subsection{Antioxidant Activity}

The method described by [8] was used. This method is based on reduction of an alcoholic solution of DPPH in the presence of a hydrogen donor antioxidant. The calculated amount of antioxidants in the sample required to reduce the initial concentration of DPPH radical 50\%. The DPPH radical was dissolved in 95\% ethanol, $2.5 \mathrm{ml}$ of DPPH solution equal to 1.0 absorbance were taken aliquots of the extract were added. Efficiency values of concentration were made after 10 minutes of reaction, decreasing absorbencies was recorded at 1 minute intervals. Worked at $515 \mathrm{~nm}$ as the peak wavelength in a UV-Visible Spectrophotometer Perkin Elmer Lambda 25, DPPH radical concentration in the reaction medium was calculated by nonlinear from a calibration curve obtained for different concentrations of extract concentration vs. regression DPPH radical.

The antiradical activity (AAR) was calculated by the equation:

$$
\operatorname{AAR}(\%)=100\left[1-\frac{\mathrm{A}_{m}^{\infty}}{\mathrm{A}^{0}}\right]
$$

where:

$\mathrm{A}^{0}$ : absorbance at time 0 sample without added.

$\mathrm{A}_{m}^{\infty}$ : sample absorbance obtained in steady state by adjusting the kinetic profiles at infinite time.

However, the results obtained by this method are reported as IC50 that is the median inhibitory concentration, that is, the concentration of antioxidant compounds that can inhibit 50\% of DPPH radical. 


\section{Data Analysis}

The results were analyzed by one-way ANOVA $(p<0.05)$ and LSD test was used to compare means. STATGRAPHICS Plus software was used

\section{Results}

Content of total phenols Phenolic compounds are very important plant constituents because of their ability to sequester free radicals, which is related to the presence of the hydroxy group. In Table 1, the concentration of total phenolic compounds from each fraction for all four strains of Cucurbita spp seeds shown.

Total flavonoid content: the results (Table 2) showed lower values than those obtained for the analysis of phenols. This is within expected, being that flavonoids are a subgroup of the phenolic compounds.

Antioxidant activity: the results indicate that the antioxidant activities of all varieties of Cucurbita spp seeds were able to trap DPPH radical a concentration dependent manner. The antioxidant activity of these expressed as median inhibitory concentration (IC50) is shown in Figure 2.

Table 1. Total phenols in extracts of pumpkin seeds, acid Galico umol/g acid extract.

\begin{tabular}{|c|c|c|c|c|c|}
\hline Variety $\quad$ Ex & $\mathbf{W}$ & $\mathbf{M}$ & Ac & Ac Et & Cont. Total \\
\hline CMi & $67.48 \pm 1.22$ & $95.96 \pm 3.25$ & $48.72 \pm 3.46$ & $80.91 \pm 1.89$ & $275.10 \pm 6.86$ \\
\hline CMo & $14.15 \pm 0.20$ & $70.78 \pm 0.20$ & $22.57 \pm 1.40$ & $11.29 \pm 0.21$ & $118.79 \pm 3.72$ \\
\hline $\mathbf{T}$ & $25.06 \pm 0.78$ & $68.80 \pm 1.48$ & $29.49 \pm 2.67$ & $42.12 \pm 0.67$ & $165.48 \pm 0.94$ \\
\hline CMa & $53.88 \pm 0.58$ & $62.79 \pm 3.34$ & $30.75 \pm 2.76$ & $47.49 \pm 0.13$ & $212.87 \pm 7.51$ \\
\hline
\end{tabular}

*Fractions: W: aqueous, M: methanol, Ac: acetone; Ac Et: ethyl; ${ }^{* *}$ Variety seed. CMi: C. mixta Pangalo; CMo: C. moschata (Duchesne ex Lam.) Duchesne ex Poir, T: Between hybrid C. moschata and C. maxima Duchesne ex Lam, MCa. C. maxima Duchesne.

Table 2. Total flavonoids in extracts of pumpkin seeds, Quercetin as mg/g extract.

\begin{tabular}{|c|c|c|c|c|c|}
\hline Variety $E x$ & $\mathbf{W}$ & $\mathbf{M}$ & Ac & Ac.Et & Cont. Total \\
\hline CMi & $1.35 \pm 0.05$ & $1.421 \pm 0.15$ & $39.12 \pm 1.94$ & $54.74 \pm 0.46$ & $96.63 \pm 1.14$ \\
\hline CMo & $0.43 \pm 0.07$ & $0.41 \pm 0.04$ & $25.64 \pm 0.12$ & $53.55 \pm 0.21$ & $80.02 \pm 0.18$ \\
\hline $\mathbf{T}$ & $1.72 \pm 0.08$ & $0.53 \pm 0.01$ & $20.66 \pm 1.02$ & $9.27 \pm 0.18$ & $32.03 \pm 1.39$ \\
\hline CMa & $0.48 \pm 0.06$ & $0.29 \pm 0.33$ & $24.23 \pm 1.85$ & $52.77 \pm 0.05$ & $77.77 \pm 1.82$ \\
\hline
\end{tabular}

*Fractions: W: aqueous, M: methanol, Ac: acetone; Ac Et: ethyl; ${ }^{* *}$ Variety seed. CMi: C. mixta Pangalo; CMo: C. moschata (Duchesne ex Lam.) Duchesne ex Poir, T: Between hybrid C. moschata and C. maxima Duchesne ex Lam, MCa. C. maxima Duchesne.

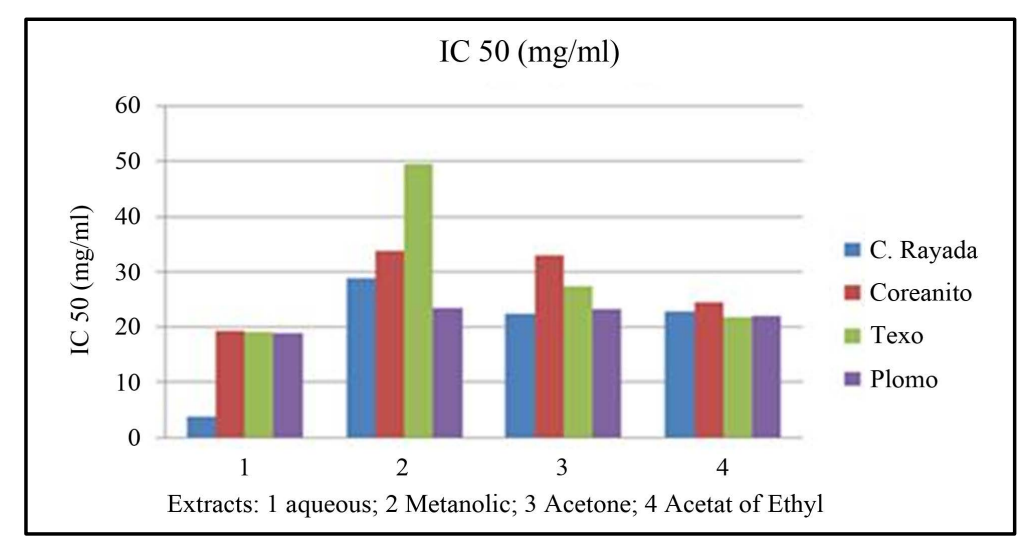

Figure 2. Median inhibitory concentration of pumpkin seed extracts. IC 50 (mg/ml). 


\section{Discussion}

Phenolic compounds have a significant action on the stabilization of lipid oxidation, have been associated with antioxidant activity and are suggested to have inhibitory effect on mutanogénesis and carcinogenesis [9]. The highest values of total phenols were observed in the methanolic fractions of the four varieties of Cucurbita spp with values ranging from 10.68 to $16.32 \mathrm{mg} \mathrm{GA} / \mathrm{g}$ extract , higher turn that reported by [10] who found values in the methanol fraction of 0.09 to $0.20 \mathrm{mg} \mathrm{GA} / \mathrm{g}$ extract, pumpkin seeds, and are also higher than those reported by other authors [11] (1.58 mg AG/g flour) and methanol extracts of pumpkin seed oil [12] which reported a value of $0.98 \mathrm{mg} \mathrm{AG} / \mathrm{g}$ oil. In turn, high concentration of phenolic compounds in the aqueous fraction can be attributed to the presence of proteins and other water soluble compounds containing phenolic rings are obtained , with C. mixta Pangalo (67.48 $\pm 1.22 \mathrm{~mol} \mathrm{GA} / \mathrm{g}$ extract) and C. maxima Duchesne (53.88 $\pm 0.58 \mathrm{~mol} \mathrm{GA} / \mathrm{g}$ extract) varieties showed higher content in this fraction. The Folin-Ciocalteu method is widely used to measure phenols; however there may be reactions with reducing substances such as phenolic compounds or ascorbic acid sugar [13] [14].

In fractions of ethyl acetate, where the solvent is used to extract phenolic compounds is very difficult to extract some sugar to pass through, but if other than phenols and phenolic acids reduced the Folin-Ciocalteu method, because in this fraction were relevant concentrations found in all varieties of Cucurbita spp with values of $11.29 \pm 0.21$ to $80.91 \pm 1.89 \mathrm{~mol} \mathrm{GA} / \mathrm{g}$ extract. In contrast, the fractions with the lowest values ketones were observed in the quantification of total phenols. According to the spectrophotometric technique all species showed higher concentration of total flavonoids in the ethyl acetate fraction with values that ranged from 54.74 \pm 0.46 to $9.27 \pm 0.18$ ( $\mathrm{mg}$ of quercetin/g extract ) being C. mixta Pangalo the variety presented higher content, which in turn is lower than those reported by authors [2] who found values for Cucurbita argyrosperma $110 \pm$ $5.32 \mathrm{mg}$ quercetin/g of sample, but in time is greater than that reported [14] for Cucurbita moschata (quercetin $17.73 \mathrm{mg} / 100 \mathrm{~g}$ ). In all varieties of seed Cucurbita spp studied, the highest antiradical activity was detected in the aqueous fractions, highlighting C. mixta Pangalo (IC50 $3.83 \pm 0.47$ ), with higher activity than that reported by [10] for seeds Cucurbita, however these values found by [10] are higher than those found for Tetsukabuto, $C$. moschata and C. maxima Duchesne in the aqueous fraction In addition, acetone extracts of hazelnut (0.098 $\mathrm{mg} / \mathrm{ml}$ ) [15] and aqueous extract of walnut (0.15 to $0.22 \mathrm{mg} / \mathrm{ml})$ [16] appear to be more effective DPPH radical inactivating the corresponding pumpkin seed extracts.

\section{Conclusion}

The results obtained show a clear relationship between the content of total phenols, flavonoids and antioxidant activity, with C. mixta Pangalo which showed higher antioxidant activity, this species can be considered a new source of natural antioxidants, to produce a beneficial effect on health.

\section{References}

[1] Robinson, R.W. and Decker-Walters, D.S. (1997) Cucurbits. Cab International, Wallingford, Oxon, New York.

[2] Caceres, A., Lange, K., Cruz, S., Velásquez, R., Sequeda, L. and Lima, S. (2009) Actividad antioxidante de diez especies nativas como posibles preservantes de alimentos y fuente para el desarrollo de nutracéuticos. Informe Final Proyecto FODECYT, Guatemala.

[3] Espin, J.C., Soler-Rivas, C., Wichers, H.J. and García-Viguera, C. (2000) Anthocyanin-Based Natural Colorants: A New Source of Antiradical Activity for Foodstuff. Journal of Agricultural and Food Chemistry, 48, 1588-1592. http://dx.doi.org/10.1021/jf9911390

[4] Fukumoto, L.R. and Mazza, G. (2000) Assessing Antioxidant and Prooxidant Activities of Phenolic Compounds. Journal of Agricultural and Food Chemistry, 48, 3597-3604. http://dx.doi.org/10.1021/jf000220w

[5] Yu, J., Vasanthan, T. and Temelli, F. (2001) Analysis of Phenolic Acids in Barley by High-Performance-LiquidChromatography. Journal of Agricultural and Food Chemistry, 49, 4352-4358. http://dx.doi.org/10.1021/jf0013407

[6] Singleton, V., Orthofer, R. and Lamuela-Raventós, R. (1999) Analysis of Total Phenols and Other Oxidation Substrates and Antioxidants by Means of Folin-Cicalteau Reagent. Methods in Enzimology, 299, 154-178.

[7] Popova, M., Bankova, V., Butovska, D., Petkov, V., Nikolova-Damyanova, B., Sabatini, A.G., Marcazzan, G.L. and Bogdanov, S. (2004) Validated Methods for the Quantification of Biologically Active Constituents of Poplar-Type Propolis. Phytochemical Analysis, 15, 235-240. http://dx.doi.org/10.1002/pca.777 
[8] Brand-Williams, W., Cuvelier, M.E. and Berset, C. (1995) Use of a Free Radical Method to Evaluate Antioxidant Activity. LWT-Food Science and Technology, 28, 25-30.

[9] Ortiz, H., Barragan, H. and Murillo, E. (2007) Poder antioxidante de los flavonoides de hoja y corteza de bauhinia kalbreyeri harms (casco de vaca). Scientia et Technica, 13, 209-210. http://www.redalyc.org/pdf/849/84903355.pdf

[10] Xanthopoulou, M.N., Nomikos, T., Fragopoulou, E. and Antonopoulou, S. (2009) Antioxidant and Lipoxygenase Inhibitory Activities of Pumpkin Seed Extracts. Food Research International, 42, 641-646. http://dx.doi.org/10.1016/j.foodres.2009.02.003

[11] Parry, J.W., Cheng, Z., Moore, J. and Yu, L. (2008) Fatty Acid Composition, Antioxidant Properties, and Antiproliferative Capacity of Selected Cold-Pressed Seed Flours. Journal of the American Oil Chemists' Society, 85, 457-464. http://dx.doi.org/10.1007/s11746-008-1207-0

[12] Parry, J., Hao, Z., Luther, M., Su, L., Zhou, K. and Yu, L. (2006) Characterization of Cold Pressed Onion, Parsley, Cardamom, Mullein, Roasted Pumpkin, and Milk Thistle Seed Oils. Journal of the American Oil Chemists' Society, 83, 847-854

[13] Robinson, R.W. and Decker-Walters, D.S. (1997) Cucurbits. Cab International, Wallingford, Oxon, New York.

[14] Ojiako, O.A. and Igwe, C.U. (2007) Nutritional and Anti-Nutritional Compositions of Cleome rutidosperma, Lagenaria siceraria, and Cucurbita maxima Seeds from Nigeria. Journal of Medicinal Food, 10, 735-738. http://dx.doi.org/10.1089/jmf.2007.625

[15] Alasalvar, C., Karamac, M., Amarowicz, R. and Shahidi, F. (2006) Antioxidant and Antiradical Activities in Extracts of Hazelnut Kernel (Corylus avellana L.) and Hazelnut Green Leafy Cover. Journal of Agriculture and Food Chemistry, 54, 4826-4832. http://dx.doi.org/10.1021/jf0601259

[16] Pereira, J.A., Oliveira, I., Sousa, A., Ferreira, I.C.F.R., Bento, A. and Estevinho, L. (2008) Bioactive Properties and Chemical Composition of Six Walnut (Juglans regia L.) cultivars. Food and Chemical Toxicology, 46, 2103-2111. http://dx.doi.org/10.1016/j.fct.2008.02.002 